
Revue
de I'histoire des religions
Revue de l'histoire des religions
$3 \mid 2009$
La culture gallicane. Références et modèles (droit, ecclésiologie, histoire)

\title{
L'électron libre du gallicanisme : Jean de Launoy
}

(1601-1678)

The "Free Electron" of Gallicanism: Jean de Launoy

Jacques Grès-Gayer

\section{OpenEdition}

\section{Journals}

Édition électronique

URL : http://journals.openedition.org/rhr/7284

DOI : $10.4000 /$ rhr.7284

ISSN : 2105-2573

Éditeur

Armand Colin

Édition imprimée

Date de publication : 1 juillet 2009

Pagination : $517-543$

ISBN : 978-2200-92591-8

ISSN : 0035-1423

Référence électronique

Jacques Grès-Gayer, "L'électron libre du gallicanisme : Jean de Launoy (1601-1678) », Revue de

I'histoire des religions [En ligne], 3 | 2009, mis en ligne le 01 juillet 2012, consulté le 02 mai 2019. URL

http://journals.openedition.org/rhr/7284 ; DOI : 10.4000/rhr.7284 


\section{JACQUES GRÈS-GAYER}

The Catholic University of America, Washington D.C.

\section{L'électron libre du gallicanisme : Jean de Launoy (1601-1678)}

Longtemps considéré comme un gallican extrême, le docteur de Navarre $J$. de Launoy était surtout un érudit original et indépendant. L'étude de ses écrits, en particulier un recueil thématique de lettres, met en évidence une vision plus classique; elle établit la spécificité de sa contribution aux débats ecclésiologiques et canoniques du temps. En démontrant de manière scientifique la vérité historique et théologique de la doctrine de France, il affaiblissait les perspectives tridentines et établissait un modèle d'Église apte à satisfaire les aspirations de nombreux chrétiens.

\section{The "Free Electron" of Gallicanism : Jean de Launoy}

Long perceived as an extreme Gallican, the Navarre Doctor J. de Launoy was above all an independent and original scholar. A study of his writings, in particular a thematic collection of letters, exposes a more classical vision of him; it establishes the singularity of his contribution to the ecclesiastical and canonical debates of his time. In systematically proving the historical and theological truths of the Doctrine of France, he weakened Tridentine perspectives and established a model of the Church capable of responding to the yearnings of many Christians. 


\section{L'ARISTARQue DE SON SIÈCLE}

En tant que doctrine cohérente et stable, le « gallicanisme », on le sait, n'existe pas vraiment. Comme tous les termes génériques forgés au XIX ${ }^{\mathrm{e}}$ siècle, le mot donne l'impression trompeuse d'un ensemble structuré et homogène, alors que n'existent que des " gallicanismes » mis en place selon les circonstances et leurs perspectives particulières par des personnages ou des groupes influents. De toute évidence, depuis 1682, les Quatre Articles de la Déclaration du Clergé représentent une référence normative, mais la manière même dont ils sont présentés et commentés confirme ce caractère essentiel de la doctrine de France : sa souplesse et même sa fluidité. La meilleure démonstration en a été fournie par Aimé-Georges Martimort, dans un travail qui fait autorité et où il exposait le développement du " gallicanisme de Bossuet»: en le replaçant de manière admirable dans son contexte historique, il a montré comment s'est mise en place une vision personnelle, qui représente la facette la plus influente de cet ensemble à géométrie variable ${ }^{1}$. Ensemble variable, car quel qu'il soit le gallicanisme est avant tout une réaction contre une vision du catholicisme perçue comme ultramontaine, c'est-à-dire faisant trop de part à la papauté tridentine, à ses représentants et surtout à ses défenseurs. Opposition dialectique, qui correspond bien à la manière dont se déroulent et parfois se résolvent les querelles théologiques, avec la complication propre à ce cas d'espèce, puisqu'il concerne non seulement le pouvoir dans l'Église (la puissance ecclésiastique) mais aussi ses rapports avec le pouvoir politique (la puissance séculière). Pour bien le comprendre, il faut donc suivre ce débat complexe au niveau même des arguments échangés par ceux qui s'y engagent. Une des meilleures démonstrations de cette dialectique se trouve dans les écrits du docteur Jean de Launoy, une figure gallicane emblématique dont la pensée est encore mal connue ${ }^{2}$. Il suffit de consulter ses ouvrages pour en comprendre la raison : une méthode cumulative par empilage de citations, un ton doctoral, c'est-à-dire

1. Aimé-Georges Martimort, Le gallicanisme de Bossuet, Paris, 1953.

2. Ibid., p. 167-168. 
sentencieux et souvent méprisant, un style élaboré et difficile (il écrit en latin) et surtout une agressivité à fleur de peau. Plus apte à l'attaque et à la riposte qu'à l'exposition sereine, Launoy est un théologien à l'ancienne, un controversiste, un disputant, un intellectuel pur, diront certains. Mis à l'abri du besoin par un éminentissime protecteur, il peut se permettre bien des audaces, d'où la réaction de Bossuet qui fit arrêter ses trop libres conférences du lundi où se pressait 1'intelligentsia européenne ${ }^{3}$. Si c'est pour sa méthode critique que mérite d'être célébré «l'Aristarque de son siècle »", il est aussi évident que son engagement gallican, fruit d'une telle méthode, mérite aussi une investigation. Par ses idées, mais aussi par sa manière de les exposer, il contribue à une meilleure connaissance de cet ensemble encore imprécis qui est l'objet de notre réflexion commune.

\section{Mise en place du gallicanisme}

Le gallicanisme de Launoy se trouve disséminé dans les dix infolios publiés en 1731-32 par l'abbé Granet ${ }^{5}$, qui représentent ses œuvres complètes ou plutôt celles qui ont survécu car, d'après le catalogue qu'il a dressé, près de la moitié des titres a disparu'. À son habitude, ce sont des études pointilleuses où l'on note cependant une continuité de propos, qui a sûrement influencé ceux à qui était destinée cette érudition. Cela ne suffirait pas pour en tirer une théorie particulière, ni même pour valider la réputation qu'il s'est acquise

3. En 1676. Les dernières années de Bossuet. Journal de Ledieu, éd. Ch. Urbain et E. Levesque, Bruges, 1929, II, p. 297. « Où l'on peut dire qu'il se formait plus de défenseurs de nos Libertés que partout ailleurs ». Lettre d'un abbé à un prélat de la Cour de Rome sur le Décret de l'Inquisition du 7 décembre 1690, Toulouse, 1691, p. 57-58 (à propos du décret anti-janséniste d'Alexandre VIII).

4. Bruno Neveu, "La vie érudite à Paris ", dans Érudition et religion aux XVII" et XVIII" siècles, Paris, 1994, p. 69. Jacques M. Grès-Gayer, " "L'Aristarque de son siècle", le Dr Jean de Launoy (1601-1678) », dans Jean-Louis Quantin et JeanClaude Waquet, Papes, princes et savants dans l'Europe moderne. Mélanges à la mémoire de Bruno Neveu, Genève, 2006, p. 269-285.

5. Joannis Launoii, Constantiensis, Parisiensis theologi, Socii Navarrcei, Opera omnia ad selectum ordinem revocata, éd. F. Granet, Cologne, 1731-1732 [abrégé $O .0$. ].

6. 310 opuscules disparus. Catalogus variorum opusculorum Joannis Launoii Constantiensis, theologi parisiensis, in O. o., IV-2, p. 482-491. 
de défenseur des Libertés gallicanes ${ }^{7}$. Celle-ci est fondée sur un peu ordinaire recueil de Lettres dans lequel il expose plus systématiquement ses idées. Dans cette correspondance publiée entre 1667 et $1673^{8}$, avant d'être réunie dans une influente édition anglaise ${ }^{9}$, il aborde les principaux points qui caractérisent sa vision personnelle. Il s'agit avant tout d'ecclésiologie avec quelques ouvertures judicieuses sur le droit canonique. Launoy, nous dit-on, avait choisi ce procédé pour éviter la censure ${ }^{10}$; en réalité si quelques lettres semblent correspondre à un véritable échange épistolaire ${ }^{11}$ où se distingue clairement un réseau gallican ${ }^{12}$, pour la plupart il ne s'agit que d'un subterfuge, distribuant à différentes personnes les parties successives d'une recherche thématique ${ }^{13}$ : la coloration nationale est indéniable, mais c'est surtout l'esprit critique qui domine, correspondant en cela à la méthode favorite du Docteur de Navarre.

7. «Docteur des Libertés gallicanes », Mercure Galant, mars 1678, p. 223. « Jurium Ecclesice et Regis acerrimus vindex ». Bayle, Dictionnaire, remarque N.

8. Joannis Launoii [...] Epistolarum Pars $1^{a}\left[8^{a}\right.$ ], Paris, 1667-1673.

9. Epistolce omnes 8 partibus comprehensce, nunc demum simul editce, Cambridge, 1689 [W. Saywell, éd]. O. o., V-1-2.

10. «C'est même comme un miracle que nous ayons ce qu'il a fait imprimer durant sa vie pour la supériorité des conciles et contre l'infaillibilité des papes et sur d'autres sujets de cette nature, et nous le devons à l'invention dont il s'avisa, qui fut de le donner par morceaux dans des lettres qu'il adressait aux uns et aux autres, se délivrant par ce moyen de la servitude insupportable de la censure de certains docteurs de son temps, sans l'agrément desquels nul privilège n'était expédié et qui paraissaient gagés pour arrêter tous les bons livres et faire desespérer les auteurs. » Lettre d'un abbé à un prélat de la Cour de Rome, op. cit., p. 58.

11. Il fait allusion au début de nombreuses lettres à une question soulevée par son interlocuteur, ou à une réponse reçue à une lettre précédente. Ainsi $O . o$., V-1, p. 93, i-9, À Ch. Fauveau (31 août 1664) : "Obsecras me, cum pro lege amicitice nostrce et pro jure vetustioris in eadem Facultate magisterii jubere possis, ut ad te perscribam, num Bellarminus [...] sincere proponat statum quastionis ». O. o., V-1, 1-2, p. 13, À A. Faure (21 sept. 1664).

12. Les docteurs Le Vaillant [70], Le Noir [83], Fortin [177], Breyer [335], Petitpied [322], Faure [325], Marais [353], Ratouyn [351], Roulland [404], Boileau [590] sont parmi les gallicans les plus typés. J. M. Grès-Gayer, Le Gallicanisme de Sorbonne, Paris, 2002, p. 381. On note la tentative d'approche de Gerbais [385], un modéré. O. o., V-1, p. 243, ii-6 (1 ${ }^{\text {er }}$ jan. 1665). Le $\mathrm{n}^{\circ}$ entre crochets renvoie au tableau des docteurs de la Faculté de théologie de Paris publié dans : Le Gallicanisme de Sorbonne, p. 467-525. Voir en annexe la liste des correspondants.

13. Ainsi la série sur l'indiction et la convocation des conciles [v-1 à 11], ou celle sur la présidence des huit premiers conciles généraux [viii-1 à 10]. Dans ces lettres, il renvoie aux précédentes ou futures. Ainsi, O. o., V-1, p. 103, v-7, À G. Voël (30 juin 1666). 


\section{LA MÉTHODE DE LAUNOY}

En 1633, comme tout candidat à la licence en théologie, J. de Launoy soutint des thèses de Majeure et Mineure ordinaires ${ }^{14}$ : on peut penser que comme beaucoup, il chercha à briller en défendant des positions originales sinon inédites, en ce cas, le pouvoir exclusif de l'État sur les empêchements au mariage ${ }^{15}$. Cet art de la provocation allait vite devenir la marque distinctive du personnage, toujours prêt à soulever une question à partir d'éléments historiques et théologiques susceptibles d'affaiblir ou même de détruire l'opinion généralement acceptée. Inévitablement, ses écrits attiraient l'attention de quelque contemporain, et s'il commettait l'erreur de lui répondre, s'ensuivait une polémique où l'on pouvait être sûr que Launoy aurait le dernier $\operatorname{mot}^{16}$. Par son érudition, bien entendu, mais aussi par sa technique, en particulier l'utilisation de l'argument ad hominem, selon le principe de Tertullien : Optimum argumenti genus quod ob adversario sumitur, c'est-à-dire de reprendre les termes mêmes d'un auteur pour les retourner contre lui ${ }^{17}$. Son but déclaré était, bien évidemment, la Vérité immuable ${ }^{18}$ : c'est en cela qu'il a été perçu comme Le Critique par excellence, appliquant avec rigueur une méthode dont il rappelle sans relâche à ses interlocuteurs les exigences et les lois. Il avait aussi des préoccupations plus concrètes, dont la résistance au "romanisme» paraît la principale. Si l'on retrouve dans ses écrits gallicans le ton critique et acerbe qui est sa marque, il est notable de constater que dans cet ensemble la polémique directe est absente, comme s'il

14. Sur le parcours universitaire dans la Faculté de Théologie de Paris. J. M. Grès-Gayer, «Tradition et modernité. La réforme des études en Sorbonne (1673-1715) », Revue d'histoire de l'Église de France, t. 88, 2002, p. 341-389.

15. En ces deux occasions, il défendit le pouvoir exclusif du Prince d'établir des empêchements dirimants du mariage, un sujet sur lequel il reviendra plusieurs fois. O. o., I, p. 635. Voir infra, n. 74.

16. «L'Aristarque de son siècle », art. cit., p. 275-277.

17. J. Boileau, Traité des empêchements du mariage, dans J. de Launoy, O. o., IV-2, p. 303.

18. À L. Cousin (12 mai 1677), O. o., V, Supplément-6, 826, où il cite Tertullien [Liber de velandis virginibus, ch. 1]: «Nemo Veritati prcescribere potest, non spatium temporum, non patrocinia personarum, non privilegium regionum », et l'axiome du Droit: "Cursus temporis non mutat substantiam veritatis ». "Veritatis Assertor Perpetuus", disait l'épitaphe refusée par les Minimes. Niceron, Mémoires, XXXII, p. 88. 
n'avait pas trouvé d'interlocuteur à sa mesure ${ }^{19}$. Les auteurs à qui il s'oppose sont en général tous disparus, théologiens jésuites pour la plupart à qui il reproche leur mauvaise foi et leur manipulation des textes, et parmi eux, l'ennemi numéro un, Robert Bellarmin. Quelques dominicains aussi parmi ses adversaires, choisis pour leur parti pris scolastique, en particulier Thomas de Vio, cardinal Cajetan. Celui-ci, on s'en souvient, avait eu une vive polémique avec un jeune docteur de Paris, Jacques Almain, sur les pouvoirs du concile et du pape ${ }^{20}$. De toute évidence, cette dispute est pour Launoy emblématique, car c'est le sujet récurrent de son exposition gallicane ${ }^{21}$, mais il prend bien soin de le replacer dans son contexte véritable : l'Église.

\section{L'ÉGLISE}

Launoy partage avec tous les défenseurs des Libertés gallicanes une conception fixiste d'un âge d'or du christianisme dont seule l'Église nationale aurait gardé la mémoire et maintenu l'esprit. C'est donc au nom de cette connaissance de l'antiquité chrétienne et du déclin historique de ses valeurs qu'il va procéder dans sa critique exhaustive des nouveautés induites par les «adulateurs de la curie romaine $\gg^{22}$ responsables, selon lui, d'un affaiblissement qu'il déplore et cherche à renverser ${ }^{23}$.

L'objet principal de la réflexion de Launoy est l'Église, « le rassemblement du peuple fidèle uni par une même foi ». S'il en pré-

19. Une seule exception: le P. Vincent Baron, o. p. (1604-1674), qui avait pris la défense de Thomas d'Aquin critiqué par Launoy. O. o., V-2, p. 148-208, v-9, À Th. Fortin (30 août 1666), et 319-411, vi-14, À L. Marais (1 $1^{\text {er }}$ août 1667).

20. O. de la Brosse, le Pape et le concile : la comparaison de leur pouvoir à la veille de la Réforme, Paris, 1965.

21. O. $o$, V-1, p. 34-47, i-5, À R. Fromentin (28 juin 1664).

22. O. o., V-1, p. 371, iii-5, À M. Le Metayer (5 août 1665); ibid., p. 380, 396, iii-7, À Ch. Fauveau (1 ${ }^{\text {er }}$ sept. 1665); ibid., p. 450, 452-454, iv-2, À Fr. Bon (15 oct. 1665). O. o., V-2, p. 183, v-9, À Th. Fortin (30 août 1665).

23. O. o., V-1, iv-5, p. 33, À Fr. Bon (13 juin 1664) avec la citation de Célestin I aux prêtres des Gaules, "hoc verbis quatuor, sed expressis et significantioribus declarat: Desinat incessere novitas vetustatem. " Aussi, Sixte I à Jean d'Antioche «Nihil ultra liceat novitati, qui nihil adjici convenit vetustati », V-2, p. 218, À H. Montmorin (6 déc. 1666). Citations plusieurs fois reprises, V-2, p. 435, vii-2, À M. Girard (15 oct. 1669) et ibid., p. 685, viii-13, À N. Gatin (22 juin 1673). 
sente dans son œuvre plusieurs définitions puisées dans l'Écriture et les Pères ${ }^{24}$, c'est toujours pour réfuter les « abus » de Canisius, puis de Bellarmin, qui les ont modifiées en ajoutant la soumission aux pasteurs légitimes, principalement au pape. Interpolation douteuse, juge-t-il, et regrettable source de division au sein du catholicisme ${ }^{25}$. Même les théologiens gallicans les plus favorables à la romanité n'ont eu garde de la reprendre ${ }^{26}$.

Cette définition, qui refuse l'identification de l'Église à « l'ordre sacerdotal $»^{27}$ et d'une certaine manière relativise la hiérarchie, est essentielle pour Launoy : comme elle va très loin, il a dû la justifier dans un rare écrit français, qui est tout à fait explicite :

Le concile [de Trente, dans son décret sur le mariage] ne prend pas le mot d'Église pour l'ordre sacerdotal seulement ou pour une assemblée de prélats, mais pour une assemblée de fidèles, comme le sens commun le fait voir et l'usage l'enseigne. [...] On ne finirait point si l'on voulait rapporter tous les endroits de ce concile où le mot d'Église est manifestement pris pour l'assemblée des fidèles, c'està-dire un corps composé de plusieurs membres. Lesquels, quoiqu'ils soient différents et qu'ils aient différentes fonctions, sont attribuées à ce même corps, tantôt ratione partis, tantôt ratione totius, comme parle Cajetan ${ }^{28}$.

24. O. o., V-2, p. 665-695, viii-13, À N. Gatin (22 juin 1673). Dans l'Écriture Ecclesia Dei est Societas fidelium, ibid., p. 667. Chez les Pères et les auteurs ecclésiastiques : «Agregatio, Collectio, Multitudo, Convocatio et surtout Congregatio fidelium ». Ce que le Catéchisme romain (1545) résume : « Fidelium congregatio, quo a Deo ad vitam ceterna ordinata \& electa est ». Ibid., p. 680.

25. O. o., V-2, p. 684: «Et Hoec abunde sufficiunt [...] derivatam ab Apostolis definitionem Ecclesice ab illustrioribus theologis, \& antiquce traditionis amatoribus, \& tempore Tridentini concilii, \& post tempus ejusdem concilii retentam fuisse.» Mais Casinius et Bellarmin ont changé cela: "Antiquam definitionem interpolarunt, aut contra bonce definitionis, vel etiam descriptionis regulas auxerunt, et auctarium suum insigni discordia nobilitarunt. »

26. O. o., V-2, ibid., p. 686 : André Duval, lui-même, n'admet pas cette définition et il s'en tient à la définition classique : «Societas fidelium in vero Dei cultu inter se communicantium ». Il ajoute : «Huic autem aliqui addunt sub uno Pastore Christi Vicario, sed hoc magis ad statum Ecclesice, quem in novo Testamento a Christo Domino accepit. Proterea ad statum Ecclesice hujus vitce potius, quam ad ejus essentiam ab unoquoque statu abstrahentem spectat. »II $I I^{e}$, Tractatus de Fide, art. 1.

27. Le moyen de rectifier les Six propositions que la Faculté de Théologie donna au Roi, l'an 1663, in O. o., IV-2, p. 129.

28. Observations sur l'acte de Vespéries de M. Leullier, Licencié en théologie, qui a été soutenu dans les Écoles du collège de Sorbonne l'an 1676, le 8 juin, in O. o., I, p. 1009. 


\section{Puissance ecclésiastique}

C'est donc à l'Église ainsi définie que le Christ a confié sa propre autorité ou, comme on dit, sa puissance. Catholica Ecclesia est subjectum proximum Ecclesiastica potestatis : c'est la doctrine des Parisiens ${ }^{29}$ qui, le rappelle le docteur de Navarre, ne fait que reprendre celle de l'Église d'Afrique ${ }^{30}$. Comme l'exposent les commentaires des principaux textes, c'est au nom de l'Église et comme garant de son unité que Pierre a reçu du Christ les clefs du royaume. Cette perspective, qui dans ce contexte n'a rien d'original, a pour notre auteur deux conséquences principales. La première, sur laquelle il insiste particulièrement, est la "constitutionnalité » : Ecclesia canones regenda ${ }^{31}$, comme le prouvent soixante-deux passages de pontifes romains ${ }^{32}$ ou comme le recommandait à Paul III le Consilium de emendanda Ecclesia: Ecclesiam jure, non auctoritate, canone, non arbitrio proprio regendam est $t^{33}$. Il existe donc une Loi fondamentale de l'Église ${ }^{34}$, observée fidèlement aux premiers temps ${ }^{35}$, sur laquelle tous sont tenus de se régler.

29. O. o, V-1, p. 213-242, ii-5, À A. Le Vaillant [70] ( $1^{\text {er }}$ jan. 1665).

30. Citant S. Cyprien : « Sic datce sunt claves Ecclesice, sed eas Petrus unus accepit, ut Ecclesice unitatem commendaret ». Ibid., O. o., V-1, p. 216, et Optat [Lib. contra Parmenianum] : "Ecclesia corpus est, quod per illa membra suos actus exercet. [...] Ecclesiam in persona Petri claves accepisse. Sed ut unitatis negotium formaretur, solus illas Petrus accepit. » Ibid., p. 217.

31. O. o, V, p. 556, iv-7, À H. Barillon (13 fév. 1666). Il défend en particulier Adrien VI diffamé par les tenants de la Curie romaine : "Nihil prius, nihil carius, nihil antiquius observatione sacrorum Canonum habuit». Launoy donne une longue série de références, ibid., p. 556-560.

32. O. o., V-1, p. 281-307, iii-3, A Th. Roulland [404] (23 mai 1665).

33. Ibid., p. 309-310. Aussi O. o., V-1, p. 450, iv-2, À François Bon (15 oct. 1665) : «Ecclesia prceceptis Christi, documentis Apostolorum \& sacris Conciliorum canonibus regitur et suis tandem limitibus circumscribitur. » Il précise bien que cette « constitutionalité » n'est en aucune manière applicable au pouvoir séculier.

34. «Lex communis Ecclesice catholica, Evangelium, Apostoli, Prophetce, Canones Spiritu Dei conditi, \& totius mundi reverentia consecrata, \& decreta Sedis Apostolica ab his non discordantia ». Contre J. David qui attaque S. Cyprien. O. o., II-2, Examen de la Préface et de la Réponse de M. David aux Remarques sur la Dissertation du concile pleinier, dont a parlé S. Augustin en disputant contre les Donatistes, p. 194.

35. Launoy donne une longue série de références des traditions du Siège apostolique, de Grégoire IX à Innocent I. O. o., V-1, p. 556-560, iv-7, À H. Barillon (13 fév. 1666). 
La deuxième conséquence de cette conception de l'Église est la « conciliarité ». Si les clefs ont été confiées à l'Église, le pouvoir en est exercé par les ministres. Principalem potestatem a Christo Ecclesice toti collatam fuisse, qua postea per Ecclesice Ministros exerceretur $^{36}$. Il s'exerce principalement dans les conciles, qui sont la voie ordinaire pour régler les disputes doctrinales. On s'attendrait ici, dans la logique de sa conception de l'Église, à voir Launoy adhérer aux principes les plus extrêmes du conciliarisme, il se montre au contraire fort prudent. Son insistance sur la conciliarité est certes fondée sur la notion de représentation ${ }^{37}$, mais il n'en ressort pas que la participation en soit ouverte à d'autres que les évêques unis au pape. C'est en ce sens uniquement que l'on peut affirmer que le concile général ou œcuménique est le juge ordinaire des controverses dogmatiques, le concile présidé par le pape, qui en vertu de sa primauté exerce une fonction unique quoique circonscrite.

$\mathrm{Vu}$ le contexte général de ses écrits, particulièrement son hostilité envers les ultramontains, on s'attendrait à trouver chez Launoy des expressions fortes et des opinions radicales. Il rejette, en effet, les prérogatives revendiquées par ceux-ci, mais c'est pour proposer un schéma qui refuse systématiquement l'opposition entre « le pôle papauté et le pôle épiscopat $»^{38}$, au profit d'une harmonisation positive de leurs fonctions.

\section{Le pontife romain}

Loin de minimiser la primauté romaine, Launoy enseigne qu'elle est de droit divin, mais, pour lui, c'est une primauté de service. Il l'interprète suivant le concile de Constance approuvé par Martin V : supra particulares Ecclesias, non super Ecclesiam in synodum collectam $^{39}$. Il s'agit donc d'une fonction de gardien des canons,

36. O. o., V-1, p. 216, ii-v, À A. le Vaillant (1 ${ }^{\text {er }}$ jan. 1665), s'appuyant sur Optat de Milève. Aussi, p. 222 : « Cyrillus, Hieronymus, Chrisostomus, Ambrosius \& Basilius supra laudati loquuntur de potestate Ecclesice [...] quatenus per primi et secundi ordinis sacerdotes exercetur $\gg$.

37. O. o., V-1, p. 473-474, iv-3, À J. du Moulin ( $1^{\text {er }}$ nov. 1665$)$; V-2, p. 188 , v-9, À Th Fortin (30 août 1666); V-2, p. 349, vi-14, À L. Marais (1 ${ }^{\text {er }}$ août 1667), sur la question au concile de Trente.

38. Yves Congar, à propos du gallicanisme, in Catholicisme, IV, col. 1736.

39. O. o., V-1, p. 153, ii-1, À R. Fromentin (24 oct. 1664) : «Id est particularibus Ecclesiis prceesse, ut eas ad sacrorum canonum observationem compellat et cum observare noluerint, ex canonum forma castiget. » 
de supervision de la doctrine et, en cas de nécessité, d'intervention supplétive, canonis in orbe christiano vindex atque executor ${ }^{40}$. Ce qui parfois peut le conduire à se placer au dessus de ces règles qu'il entend maintenir et défendre ${ }^{41}$. Launoy, c'est évident, s'efforce de détruire les privilèges revendiqués par les ultramontains, mais c'est dans le but d'intégrer et non de dénier une fonction dont il reconnaît l'importance. Ce qu'il rejette chez eux, c'est justement la tentation de séparer le pape du corps de l'Église auquel il appartient.

Si le pape n'est donc pas supérieur au concile, si même, comme l'enseigne l'histoire, il n'a pas nécessairement l'initiative de son indiction ${ }^{42}$ et longtemps n'en a pas exercé la présidence ${ }^{43}$, de par son autorité apostolique il a une fonction spéciale. Comme celle de tout évêque ${ }^{44}$, son approbation est nécessaire à la confirmation qui assure l'infaillibilité promise à l'Église, elle est cependant d'une valeur particulière à cause du siège qu'il occupe. C'est le sens de l'expression ex cathedra dont les ultramontains ont détourné le sens ${ }^{45}$, elle n'assure en aucune manière une inerrance

40. Exemple de ce rôle supplétif du pontife romain : si un évêque ne discipline pas un pasteur propre, qui pèche contre le canon de Latran IV [Omnis fidelis], on doit s'adresser au pontife romain, «canonis in orbe christiano vindex atque executor. " Ad explicatam Ecclesice traditiones Observationes, in O. o., I-1, p. 440.

41. Le pape est soumis aux canons des conciles et il doit les suivre dans la direction de l'Église [in regenda ecclesia], il peut cependant s'en écarter [recedere] pour grande nécessité et utilité claire et certaine. Commentarium de Launii vita, IV-2, p. 374.

42. Une série de lettres [vi-1 à 9] fait le point sur la question, in $O$. $O$., V-2, p. 208-309. Cf. en particulier la réponse de la Faculté de Théologie de Paris à Charles VIII (1397) qui demandait si l'on pouvait convoquer le concile invito Romano Pontifice : O. o. V-2, p. 220-232, vi-2, à H. L. Montmorin (6 déc. 1666).

43. Une série de lettres [viii-1 à 10] fait le point sur la question: $O$. $O$., p. 553-621. «Romana Ecclesia hoc in prosidendi munere nihil sibi vindicat per Antistitum suorum traditionem, quce a Constantini cetate usque ad Caroli magni tempus decurrit. Hoc prcesidendi munus in prceteritis reliquerunt Gelasius, Vigilius, Pelagius II \& alii in professionibus fidei quas ediderunt; ubi tamen relinquendum non erat, si vere relinqui nequisset. » O. o., V-2, p. 567, viii-1, À R. Fromentin ( $1^{\text {er }}$ fév. 1673). Ibid., p. 580, viii-3 À G. Grouyn (1 $1^{\text {er }}$ mars 1673)] : Le pape Damase n'a pas présidé le concile de Constantinople, ni même ses légats. Sur ce sujet Bellarmin mêle le vrai et le faux.

44. O. o., V-1, p. 190-213, ii-4, À J. Boileau [590] (18 déc. 1664).

45. Prononcer ex cathedra, c'est le Pape à la tête du concile général. O. o., V-1, p. 361, iii-5, À M. Le Metayer (5 août 1665). Il cite des lettres à Clément V : «His in verbis, Romanum Pontificem e cathedra pronunciare, non est seorsum a Sede sua \& Concilio pronunciare, sed una cum Sancta Sede et approbante potissimum concilio pronunciare. » Même les auteurs jésuites le reconnaissent. Launoy cite 
ou infaillibilité personnelle, mais signifie celle de l'Église représentée dans l'unanimité conciliaire ${ }^{46}$, exprimée, selon sa fonction, par l'évêque de Rome. D'ailleurs, tous les honnêtes historiens le savent, les pontifes eux-mêmes l'admettent, certains papes ont erré $^{47}$, parfois gravement ${ }^{48}$. Fidèle en cela à la tradition gallicane, Launoy modère ses jugements historiques en distinguant la fonction et la personne, la sedes et le sedens ${ }^{49}$. Des hommes assis sur le siège de Pierre ont pu se tromper, mais l'erreur a été corrigée par leurs successeurs, qui ont illustré ainsi l'indéfectibilité du siège apostolique.

Toujours désireux de replacer le ministère du pontife romain dans son cadre ecclésial ordinaire, Launoy fait aussi appel à l'histoire pour expliquer les titres particuliers qui lui sont attribués. Loin de représenter la revendication d'une autorité particulière, la qualité d'episcopus ecclesice catholica, prise par Pie IV dans son approbation du concile de Trente, est une ancienne expression qui met en évidence l'orthodoxie du signataire et de l'Église

le De Institutionibus theologicis, du P. Bagot, ibid., p. 516, iv-5, À R. Fromentin (13 déc. 1665) : «Summum Pontificem, ut definiat aliquid infaillibiliter, concilium aliquod seu Synodum audire oportere, nec male dici tunc, ex Sancti Petri cathedra eum loqui, seu pronuntiare sententiam cum audito Concilio pronuntiat. »

46. Launoy fait le point sur la question, $O$. o., V-1, p. 370-372, iii-5, À M. Le Metayer (5 août 1665). Pour les auteurs gallicans, à partir du temps de Clément V : "Pontifex in sensu Gallicance Ecclesice loquatur de Petri cathedra, cum sacro approbante concilio loquitur et res fidei decernit. Gallicana Ecclesia credebat, indeficientis judicii privilegium nonnisi universa Ecclesice, cujus caput est Romanus Pontifex, et reprcesentati universam Ecclesiam Concilio datum esse. » Ibid., p. 370.

47. À ce sujet il évoque la «misérable controverse » concernant la deuxième version de la Bible Sixto-Clémentine, où les prescriptions du premier pontife ont tout simplement été supprimées par son successeur: $O$. o., V-1, p. 45, i-5, À R. Fromentin (28 juin 1664).

48. L'exemple de Jean XXII montre que «Hic Pontifex exemplo suo, eum errare posse qui ex cathedra pronunciat, ut ille contra Romance Ecclesice traditionem et fidei symbolum non semel pronunciavit, beatorum animas quamlibert purgatas, Deum ante supremum diem Judicii non esse visuras ». Point développé dans $O . o ., \mathrm{V}-1$, p. 11-12, i-1, À A. Faure (1 ${ }^{\text {er }}$ mai 1664) et ibid., p. 43-45, i-5, À R. Fromentin (28 juin 1664). Dans ce cas, « Ex cathedra loqui vel pronunciare aliud tunc nihil erat quam docere, quemadmodum Joannes XXII docebat ita, ut omnes docenti assentirentur. »

49. La Faculté de Paris s'est prononcée à ce sujet lors de la censure de Jean de Monson (1387), en faisant la distinction entre sedes et sedens. O. o., V-1, p. 536, iv-6, À H. Barillon (31 jan. 1666), point développé particulièrement par Gerson, De Examination doctrinarum, ibid., p. 538. Cf. Yves Congar, L'Église de saint Augustin à l'époque moderne, Paris, 1970, p. 398. 
locale dont il a la charge ${ }^{50}$. C'est donc une erreur de l'interpréter comme si l'Église catholique était un unique diocèse et n'avait qu'un seul évêque, les autres « évêques » n'étant que ses vicaires, administrateurs d'une préfecture apostolique ${ }^{51}$. Cela est contraire aux affirmations mêmes des papes qui rejettent le titre d'évêque universel ou œcuménique ${ }^{52}$. De même, l'appellation Vicaire de Jésus-Christ n'est pas particulière au pape, les autres évêques ${ }^{53}$, et même tous les prêtres, ont la même qualité ${ }^{54}$ : ce n'est que durant le second millénaire que les papes et la curie romaine l'ont revendiquée pour le seul pontife romain afin de soutenir sa prétendue infaillibilité ${ }^{55}$. On ne la trouve dans aucun acte conciliaire (pas même à Florence $)^{56}$. Les papes utilisent plus généralement le titre de $«$ Vicaire de S. Pierre $»^{57}$, c'est le titre «antiquissimus \& fundatissimus $»^{58}$.

\section{Évêques}

On n'est pas étonné, selon ces perspectives, de constater l'importance que Launoy attribue au ministère des évêques. Leur autorité est plénière ${ }^{59}$ et leur responsabilité doctrinale excellemment manifestée

50. O. o., V-1, p. 28, i-4, À Fr. Bon (13 juin 1664), p. 28. Première attestation par Léon I au concile de Calcédoine. Cf. Yves Congar, "Titres donnés au Pape », Concilium, 108 (1975), p. 55 : « La formule, en usage à partir du IV siècle désigne l'Église locale de Rome, et cela même au XI ${ }^{\mathrm{e}}$ siècle chez les hommes de la réforme dite grégorienne. Elle n'a pas le sens d'« universel », mais celui de vraie Église. Elle est équivalente à Romanus Pontifex. [...] Au reste, on la trouve au III ${ }^{\mathrm{e}}$ et $I V^{\mathrm{e}}$ siècles appliquée aux autres évêques. »

51. O. o., V-1, ibid., p. 30.

52. Titre rejeté par douze fois par Grégoire I dans le livre IV de sa $32^{\mathrm{e}}$ lettre à l'empereur Maurice, etc. O. o., V-1, ibid., p. 30.

53. O. o., V-1, p. 276-297, iii-2, À M. de Marolles (13 avril 1665). Aussi V-1, p. 152, ii-1, À R. Fromentin (24 oct. 1664).

54. O. o., V-1, p. 299, iii-2, À M. de Marolles (13 avril 1665) : «Titulus hic alter, Christi Vicarius, antiquissimus quidem est, sed eum Hormisda Romanus Pontifex, Patres, Concilia \& prceclarissimi quique theologi Sacerdotibus universis attribuunt. »

55. O. o., V-1, ibid., p. 279.

56. O. o., V-1, ibid., p. 280.

57. «Beati Petri vicarius ». O. o., V-1, ibid., p. 269-278.

58. O. o., V-1, ibid., p. 278.

59. Ils sont successeurs des Apôtres, O. o., V-2, p. 103-106, v-7, À G. Voël (30 juin 1666). Les Pontifes romains les appellent souvent coepiscopus. Ibid., p. 134-147, v-8, À R. Fromentin (13 août 1666). 
dans l'assemblée conciliaire ${ }^{60}$. Chacun est responsable d'une portion de l'Église. On note que Launoy porte une attention particulière aux structures provinciales, mettant en évidence l'autorité des métropolitains ${ }^{61}$ et des décisions prises conciliairement à ce niveau ${ }^{62}$. Il souligne aussi l'importance du sacrement de confirmation, prérogative épiscopale ${ }^{63}$, et en maints endroits récuse l'exemption qui soustrait les ordres religieux à la juridiction de l'ordinaire ${ }^{64}$. Contrairement aux accusations portées contre lui ${ }^{65}$, on ne voit pas dans ses textes une grande disposition à défendre le « richérisme », c'est-à-dire les droits des curés, ou plus généralement du clergé du second ordre ${ }^{66}$. $\mathrm{S}$ 'il tient à rappeler les censures anciennes portées à ce sujet par $1^{\prime}$ École de Paris ${ }^{67}$, c'est pour affirmer l'autorité doctrinale du corps ${ }^{68}$. S'il se montre disciple de l'ancien syndic de la Faculté, c'est dans sa définition de l'Église et de la puissance ecclésiastique : lue, écrit-il dans la tradition des Parisiens, Tertullien « in toto Ecclesice corpore sacerdotium residere dicit, et ad Ecclesiam auctoritatem revocat discrimen quod inter ordinem et plebem constituitur $\gg{ }^{69}$.

En ce sens, on peut aussi s'interroger sur la manière dont Launoy interprète la séparation des puissances chère à l'École dont il suit les principes. C'est un sujet sur lequel il intervient moins qu'on ne l'attendrait. Quelques traits cependant sont en évidence.

60. C'est aux évêques [assemblés en concile] à juger des matières de foi et de mœurs et non pas à l'Inquisition romaine. $O . o ., \mathrm{V}-1, \mathrm{p} .454$, iv-3, À J. du Moulin ( $1^{\text {er }}$ nov. 1665$)$.

61. Autorité et droits des métropolitains reconnus par les premiers conciles et confirmés par les papes. $O . o$., V-2, p. 632-665, viii-12, À L. H. de Gondrin (1 $1^{\text {er }}$ juin 1673).

62. Les décisions des synodes provinciaux n'ont pas besoin de la confirmation pontificale. O. o., V-2, p. 430-440, vii-2, À M. Girard (15 oct. 1670).

63. Launoy intervient contre Sirmond pour Saint-Cyran. Commentarium de Launoii vita compectens, O. o., IV-2, p. 356, citant le Journal des Savants.

64. En particulier dans ses deux lettres contre le P. V. Baron (o. p.). O. o., V-2, p. 155-161, v-9, À Th. Fortin [177] (30 août 1668) et surtout la longue lettre contre la réponse de celui-ci, $O$. o., V-2, p. 319-411, vi-14, À L. Marais [353] (1 $1^{\text {er }}$ août 1667$)$.

65. Antoine Charlas, Tractatus de Libertatibus Ecclesiae gallicance, Rome, 1720, I, p. 125: "Joannes Launoius Doctor Parisiensis richeriance doctrince sectator fuisse videtur, vir quidem eruditus, sed censor nimis subtilis. "

66. Malgré la remarque à M. de Marolles, V-1, p. 278, iii-2 : «Sacerdotes esse Christi Vicarios ».

67. Principalement la censure de J. Vernant (1664), V-1, p. 12, i-1, À A. Faure

( $1^{\mathrm{er}}$ mai 1664); V-2, p. 152-153, v-9, À Th. Fortin (30 août 1666).

68. De Scholis celebrioribus (Paris, 1672), O. o., IV-2, p. 118-132.

69. O. o., V-1, p. 215, ii-5, À A. Vaillant (1 ${ }^{\text {er }}$ jan. 1665). 


\section{Gallicanisme politiQue}

Launoy défend, cela ne surprend guère, la complète indépendance du pouvoir temporel. Contre Bellarmin et autres « adulateurs de la curie romaine » qui revendiquent une puissance directe ou indirecte sur la temporalité des rois, il affirme avec insistance que « la Tradition du Saint-Siège apostolique et des conciles limite au domaine spirituel l'autorité pontificale $\gg^{70}$. Le Pontife romain ne peut déposer les princes hérétiques ${ }^{71}$, ni même délier leurs sujets du serment de fidélité ${ }^{72}$.

Par contre, il souligne le rôle de la puissance séculière sur des matières ecclésiastiques; faisant appel à de nombreux précédents historiques, il montre que beaucoup de conciles, généraux ou particuliers, ont été convoqués par des empereurs, des rois, des princes $^{73}$. Autre conséquence, c'est un point sur lequel il s'est fortement engagé : l'autorité des rois sur les mariages, qui leur réserve d'établir des empêchements dirimants ${ }^{74}$, « la première et la plus importante fonction d'un État séculier, soit monarchique, soit aristocratique, soit démocratique $» .^{75}$

Comme toujours chez Launoy, la vérité historique prime sur tout présupposé idéologique, aussi fondé soit-il. C'est ainsi qu'il

70. O. o., V-2, vii-7, À Th. Roulland, p. 457-474 (13 juin 1670).

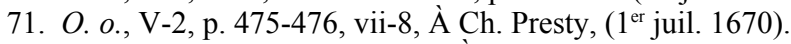

72. O. o., V-2, p. 494-524, vii-11, À R. Fromentin, (15 juil. 1670). Ce n'est pas l'objet du pouvoir de lier et de délier, partagé d'ailleurs par les évêques et les prêtres.

73. Il s'appuie principalement sur la réponse de la Faculté de Théologie de Paris à Charles VIII (1397). O. o., V-2, p. 220-232, vi-1, À L. H. Montmorin (5 déc. 1666)]; ibid., p. 251, vi-3, À G. Voël (23 déc. 1666); ibid., p. 285-292, vi-7, à L. H. Faye d'Espesse (19 jan. 1667) : «Quod Facultas nostra Parisiensis Theologice Carolo Regis VIII super certa quadam universalis Concilii cogendi ratione dedit anno MCCCXCVII. " Le rois ont aussi convoqué des conciles non généraux, V-2, p. 293-295, vi-8, À J. Sainte-Beuve (1 ${ }^{\text {er }}$ fév. 1667). Ce qui prouve bien ce que Bellarmin met en doute, disputat, que les conciles universels et particuliers ou nationaux ont bien été convoqués par les princes. Ibid., p. 295.

74. Regia in matrimonium Potestas seu Tractatus de jure scecularium Principum Christianorum in sanciendis impedimentis matrimonium dirimentibus, Paris, 1674, O. o., I, p. 625-882. Observations sur l'acte de Vespéries de M. Leullier, Licencié en théologie, qui a été soutenu dans les écoles du collège de Sorbonne l'an 1676, le 8 juin, in $O$. o., I, p. 1005-1019. Polémique avec D. Galesi, sur sa réponse à Launoy, Erratorum index locupletissimus, in $O$. o., II, p. 886-1000. J. M. Grès-Gayer « Varieties of Gallicanism. Four Sorbonne Doctors on Diriment Impediments to Matrimony (1674-1691) », The Jurist, t. 68, 2008, p. 38-52.

75. Le moyen de rectifier les Six propositions, op. cit., in O. o., IV-2, p. 129. 
demande de rectifier le premier article de la Déclaration de 1663, en admettant que, contrairement à ce qui est déclaré, les docteurs de Paris ont soutenu et enseigné la puissance directe ou indirecte du pape sur le temporel des rois, mais en affirmant aussi, au nom de la fidélité à l'Écriture et à la «véritable Tradition», que cet enseignement est "établi sur des faux raisonnements et contre les sentiments des anciens Pères, ou par des exemples corrompus ou mal entendus et par les historiens qui les rapportent sans les examiner $»{ }^{76}$

Launoy mentionne aussi le rôle du Parlement, souvent utile dans les contestations ecclésiastiques. Plutôt que d'appeler au concile, il suggère l'appel comme d'abus. Même si en France, par principe, on se doit de maintenir le droit d'appeler au futur concile, puisqu'on croit le pape inférieur au concile et capable de se tromper sur la foi ou les mœurs, il est préférable de ne pas le faire fréquemment et sans nécessité pressante. En recevant l'appel comme d'abus le Parlement casse le jugement pontifical, ou le réduit aux normes canoniques $^{77}$, ce qui dans la plupart des cas est suffisant pour régler le problème.

Bien qu'avec des nuances significatives, on retrouve donc chez le docteur de Navarre les éléments classiques de la doctrine des Parisiens. Les choix thématiques et surtout l'approche par accumulation historique mettent en évidence certains traits, ce sont ceux qui lui tiennent le plus à cœur. On trouve aussi dans sa méthode des éléments qui font ressortir l'originalité de sa contribution.

\section{Caractéristiques du gallicanisme de Launoy}

\section{Approche critique}

En dépit de l'ordre relatif et de l'apparente progression thématique des Lettres et autres écrits de Launoy, c'est leur objectif

76. Le moyen de rectifier les Six propositions, in $O$. o., IV-2, p. 129. Il rapporte les censures classiques de la Faculté à ce sujet. Cf. [Louis Ellies Du Pin], Censures et Conclusions de la Sacrée Faculté de Théologie de Paris touchant la souveraineté des rois, la fidélité que leur doivent leurs sujets, la sûreté de leur personne et la tranquilité de l'État, Paris, $1717^{1}, 1720^{2}$.

77. O. o., V-1, p. 261, ii-7, À N. Petitpied (1 $1^{\text {er }}$ mars 1665$)$. 
« critique » qui en constitue l'homogénéité. En d'autres termes, dans cet ensemble toujours susceptible d'expansion ou d'approfondissement, il aborde les sujets sur lesquels il croit nécessaire de corriger les affirmations d'auteurs qu'il estime abusés ou de mauvaise foi $^{78}$. C'est, on l'a déjà suggéré, le moteur essentiel de son activité intellectuelle ${ }^{79}$. Il n'y a donc pas chez lui la priorité d'un programme gallican, mais simplement la nécessité d'un rétablissement de la vérité sur des sujets qui lui tiennent à cœur, puisqu'il s'agit de l'Église à laquelle comme prêtre et docteur il a consacré son existence. Fidèle à sa méthode, il procède par des affirmations fortes appuyées par une accumulation de preuves qui s'appliquent, affirme t-il, aux disciplines qu'il suit. La théologie comme l'histoire étant des sciences exactes qui obéissent à des lois, il ne fait que les appliquer pour soulever ou soutenir les points qui lui paraissent importants. Il s'agit donc d'une véritable démonstration, où il a aussi à cœur de mettre en évidence l'illogisme des adversaires, en citant leurs positions contradictoires ainsi que leurs erreurs. Gallicanisme scientifique donc, réaction à l'ultramontanisme auquel il reproche sa non-observation des lois de l'histoire ${ }^{80}$ autant que de la théologie ${ }^{81}$. Il procède ici, comme il le fait à propos du culte des saints ou des privilèges monastiques, par accumulation de preuves

78. Les «crimes» de Bellarmin [crimina quibus Bellarminus sese obstrinxit] : mauvaise foi dans ses citations de textes patristiques, "Gelasium adducit ut Scripturce explicatorem, etiamsi Scriptura, non explicet ». O. o., V-2, p. 124, v-7, À G. Voël (30 juin 1666). Sur l'infaillibilité pontificale : Bellarmin agit de mauvaise foi, au point de ne pas condamner la partialité et la grande iniquité des certains auteurs. Il dissimule l'universalité, l'ancienneté et le consensus des maîtres qui attaquent sa position. Ibid., p. 420, iii-7, À L. Marais (1 ${ }^{\mathrm{er}}$ sept. 1665).

79. J. M. Grès-Gayer, "L'Aristarque de son siècle », art. cit., p. 277-279.

80. Les Lois de 1'Histoire négligées par Bellarmin, O. o., V-2, vii-9, À L. Marais (20 juin 1670), p. 477-493; négligées par Baronius, ibid., p. 456, vii-7, À J. Roulland (13 juin. 1670), ibid., p. 579-580, viii-3, À G. Grouyn (1 ${ }^{\text {er }}$ mars 1673). Aussi, De auctore vero professionis fidei, in $O$. o., II-2, p. 304. « L'Aristarque de son siècle », art. cit., p. 279.

81. Les Lois de la théologie exprimées par S. Thomas [S. T., I I Pars, qu. I, art. vii ad 2], ne sont pas observées par le Fr. V. Baron (auteur des Libri quinque apologetici pro religione, Paris, 1666), défenseur de Cajetan contre les Parisiens, "vel qui ignorat, vel qui dissimulat». O. o., V-2, p. 181, v-9, À Th. Fortin (30 août 1676). "Primum verce theologice principium : Scripturce locum adferre, qui juxta unanimum consensus Patrum acceptus. »Ibid., p. 220, vi-1, À L. H. Montmorin (5 déc. 1666), à propos de l'indiction d'un concile, par l'empereur ou le pape. 
et l'application de 1'argument négatif ${ }^{82}$ ou argument du silence ${ }^{83}$, mais pour lui la règle essentielle est celle qui a été ordonnée par le concile de Trente et explicitée par la profession de foi de Pie IV : l'Écriture interprétée selon le consentement unanime des Pères ${ }^{84}$.

\section{Gallicanisme abstrait}

De la part d'un gallican cette insistance sur la règle tridentine est astucieuse, puisque Launoy se pose en défenseur du concile qui fonde les positions qu'il entend démolir. D'autre part, l'interprétation qu'il propose des textes qu'il tente de tirer dans son sens n'a pas la rigueur qu'il exige de ses adversaires. On a déjà évoqué son exégèse de l'Ecclesia dans les décrets et canons tridentins et l'insistance à ne pas la réduire à la hiérarchie ecclésiastique, c'était une préoccupation que 1'on trouve chez d'autres gallicans influents ${ }^{85}$, mais Launoy va plus loin dans sa distinction :

Ce corps a plusieurs membres, dont les uns font une fonction et les autres en font une autre, et toutes ces fonctions quelques différentes qu'elles soient sont attribuées au même corps. Ainsi on dira que l'Église fait des empêchements de mariage, c'est-à-dire des lois civiles qui rendent les personnes inhabiles à contracter mariage, par l'entremise des princes séculiers qui font partie de cette même Eglise. Ainsi on dira que l'Église prive de la communion des sacrements ceux de son corps qui le méritent par l'entremise de ceux qui sont revêtus du sacerdoce et en sont la plus noble partie. Ainsi on dira que

82. De auctoritate negantis argumentis Dissertatio (1650), in O. o., II-1, p. 1-43. Cf. la Préface dédiée à César d'Estrées : «In omni quce agitatur qucestione, statim de antiquitate ac novitate rei disceptatur; ac si absit antiquitas, inficialia argumenta proferuntur. »

83. «L'état de la question consiste à savoir si le silence des auteurs contemporains et de ceux qui les ont suivis sur un fait est une preuve de fausseté de ce fait quand il n'est rapporté que par des auteurs qui ont vécu longtemps après et qui ne l'appuient sur l'autorité d'aucun ancien. » Louis Ellies Du Pin, Bibliothèque des Auteurs Ecclésiastiques du XVII siècle, III, p. 120.

84. «Juxta unanimum consensum Patrum acceptus». O. o., V-2, p. 71-72, v-6, À J. Boileau (13 avr. 1666).

85. Bernard Plongeron, «Une image de l'Église d'après les Nouvelles Ecclésiastiques (1728-1790)», Revue d'Histoire de l'Église de France, t. 53, 1967, p 248-268. Chantal Van der Plancke, "Une conscience d'Église à travers la catéchèse janséniste au XVIII ${ }^{\mathrm{e}}$ siècle », Revue d'Histoire ecclésiastique, t. 72, 1972, p. 134-175. J. M. Grès-Gayer, « Le gallicanisme de L. Ellies Du Pin », Lias, t. 18, 1991, p. 36-87; id. "Le gallicanisme d'A. Arnauld. Éléments d'une enquête », Chroniques de Port-Royal, t. 44, 1995, p. 31-51; id., «L'idée d'Église selon les Jansénistes et les Protestants ", Chroniques de Port-Royal, t. 47, 1998, p. 35-56. 
l'Église châtie les hérétiques de peines corporelles par l'entremise des Princes séculiers. Ainsi on dira que l'Eglise châtie les mêmes hérétiques de peines spirituelles, par l'entremise de ceux qui sont revêtus du sacerdoce ${ }^{86}$.

En d'autres termes ce «gallicanisme scientifique » n'est pas aussi détaché de la réalité qu'il le prétend. Il est vrai que Launoy s'en prend à des auteurs disparus, saint Thomas, Cajetan, Bellarmin et autres; comme il méprise leurs disciples ou épigones, il n'est pas stimulé, comme dans d'autres circonstances, par une polémique qui l'oblige à resserrer ses arguments en tenant compte des réponses des adversaires. On peut penser que s'il avait vécu plus longtemps, il aurait distingué parmi ses contemporains des adversaires plus dignes de ses attaques ${ }^{87}$. Exclu de la Faculté de Théologie pour son refus d'adhésion à la censure d'Arnauld, il n'a pas participé aux débats qui ont produit la Déclaration de 1663 et les censures de 1664, mais ses réactions critiques montrent bien qu'il les considérait trop mesurées, donc trop faibles ${ }^{88}$.

En apparence, c'est un paradoxe malgré le ton polémique qui souvent le caractérise, le gallicanisme proposé par Launoy est singulièrement modéré. On est frappé en particulier par son attitude sans passion à l'égard du pontife romain qu'il distingue systématiquement de ses sycophantes. Il ne peut s'empêcher, c'est son tempérament, d'exercer un humour souvent acide envers certains pontifes $^{89}$, mais l'on perçoit son respect de la fonction et même son

86. O. o., I-2, p. 1007. In actu Vesper. D. Leullieri Observationes.

87. Il n'a pas vécu pour connaître la réponse de J. Leullier à ses critiques, ni les efforts de J. Gerbais pour présenter une position médiane sur les empêchements dirimants. J. Boileau a tenté de le défendre, tout en reconnaissant les excès de sa position. Jules Basdevant, Des rapports de l'Église et de l'État dans la législation du mariage, du Concile de Trente au Code civil, Paris, 1900. J. M. Grès-Gayer, "Varieties of Gallicanism », The Jurist, art. cit., p. 42-46.

88. Hormis la censure de l'apologie du laxisme par Amadeus Guimenius. O. o., V-1, p. 507, iv-5, À R. Fromentin (13 déc. 1665); ibid., V-2, p. 197, v-9, À Th. Fortin ( $1^{\text {er }}$ sept. 1666); ibid., p. 330-331, vi-14, À L. Marais (1 $1^{\text {er }}$ août 1667).

89. Mémoires de G. Hermant, III, p. 361 : « M. de Launoy, docteur de Paris qui s'est toujours maintenu dans la possession de dire et d'écrire fort librement ses pensées, ne fut pas fort touché de cette constitution [Ad Sacram (1657)] qui faisait un si grand éclat dans le royaume et que le Nonce avait gardée si longtemps [...] il écrivit le 6 avril à M. de Gives, avocat du roi au présidial d'Orléans : Nous avons ici une bulle d'Alexandre VII où il y a des fautes considérables [...] Entre autres choses, il dit qu'il était in minoribus constitutus, au temps qu'il était évêque, d'où il s'ensuit que quand il appelle les évêques ses frères, il faut entendre que ce sont des frères mineurs. \ Aussi sur Cum ad aures du même, O. o., IV-5, p. 512 : 
affection pour certains papes ${ }^{90}$. Dans le contexte du temps, sa présentation de la conciliarité est notoirement modérée, détachée, ici encore, du contexte historique immédiat. Ce qui le distingue, c'est son soutien du gallicanisme politique, c'est-à-dire le régalisme, c'est en cela qu'il était richériste comme on l'en a accusé, et c'est en cela que son gallicanisme n'a eu guère de succès dans le milieu qu'il cherchait à influencer. Le lien avec les écrits de M.-A. de Dominis, faits par plusieurs, ne pouvait manquer d'affaiblir l'autorité de ses écrits; leur récupération par les milieux réformés achevait de les désavouer ${ }^{91}$.

Il reste que par ses questionnements systématiques et ses démonstrations exhaustives, cet érudit provocateur et obstiné ${ }^{92}$ a contribué solidement au mouvement gallican de son temps. Principalement en exposant les faiblesses du système des ultramontains, en démontant leurs arguments, en détruisant leurs preuves, selon un principe d'interprétation historico-théologique solide et admissible par tous les véritables savants, en mettant aussi en évidence les fondements sûrs d'une ecclésiologie authentique. Sans en tirer lui-même les conséquences, il constituait ainsi le réservoir où ont puisé pendant longtemps ceux qui cherchaient à défendre à l'intérieur ou à l'extérieur du catholicisme une autre « idée d'Église ». C'est donc à bon droit que cet «électron libre du gallicanisme » est compté comme l'un de ses meilleurs champions.

gresgayer@cua.edu

«Alexander VII, intelligens suis auribus, non oculis impositum esse, cum ad aures, inquit, nostras pervenit, Inquisitionis decretum approbat. "

90. Surtout Adrien VI. O. o., V-1, p. 43-45, 1-5, À R. Fromentin (28 juin 1664) : il reconnaît que les papes ont erré sur la foi. Ibid., p. 544-562, iv-7, À H. Barillon (13 fév. 1666). Il le défend contre le jugement du cardinal Pallavicini [fu ecclesiastico ottimo, Pontefice in verita mediocre] « et alios aulce sectatores qui Hadrianum ad regendam Sedem Apostolicam minus idoneum fuisse calumniantur. » Ibid., p. 544. Adrien VI n'a fait que mettre en pratique ce qu'il enseignait à Louvain.

91. En plus de l'édition anglicane de ses Lettres, leur analyse détaillée par J. le Clerc, Bibliothèque universelle et historique, (1690), p. 237-287, lui a fait beaucoup de tort. Cf. BnF, ms. fr. 22850, f. 77, Launoii Encomia ab Horeticis.

92. Chassé de Navarre pour avoir scandalisé les bacheliers, expulsé de la Faculté pour avoir par principe refusé de condamner Arnauld. J. M. Grès-Gayer, « L'Aristarque de son siècle », art. cit., p. 272-274. 


\section{Les Lettres de Launoy : destinataires et thématique}

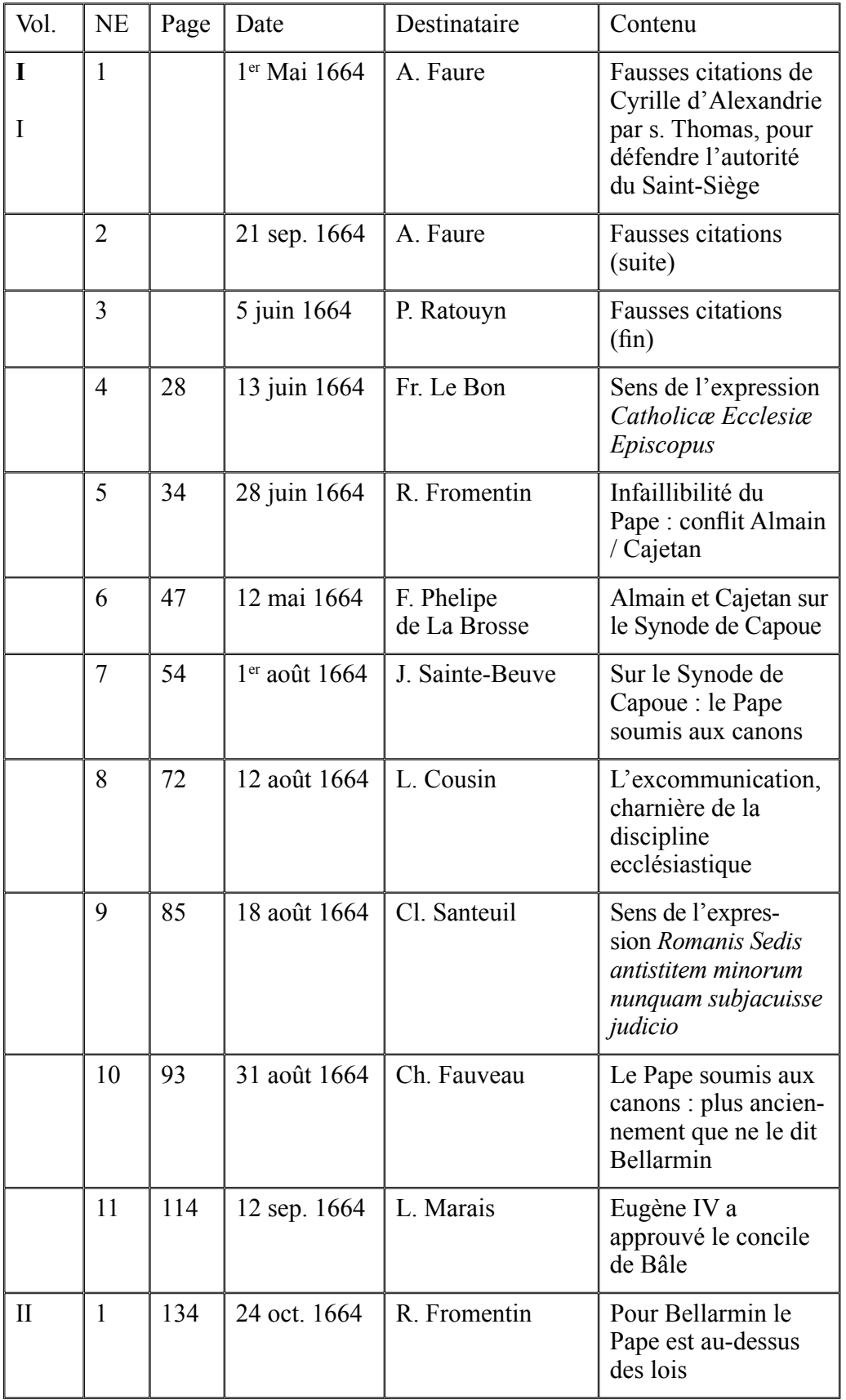




\begin{tabular}{|c|c|c|c|c|c|}
\hline & 2 & 154 & 31 oct. 1664 & $\begin{array}{l}\text { F. Phelipe } \\
\text { de La Brosse }\end{array}$ & $\begin{array}{l}\text { Les } 8 \text { textes dont } \\
\text { Bellarmin a abusés } \\
\text { pour prouver la supré- } \\
\text { matie pontificale se } \\
\text { retournent contre lui }\end{array}$ \\
\hline & 3 & 175 & 13 nov. & J. Boece, Vict. & $\begin{array}{l}\text { Appellations au } \\
\text { Saint-Siège : des } \\
\text { recours }\end{array}$ \\
\hline & 4 & 190 & 18 déc. 1664 & J. Boileau & $\begin{array}{l}\text { Confirmation des } \\
\text { conciles par le Pape }\end{array}$ \\
\hline & 5 & 213 & $1^{\text {er }}$ jan. 1665 & A. Le Vaillant & $\begin{array}{l}\text { L'Église, sujet immé- } \\
\text { diat de la puissance } \\
\text { ecclésiastique }\end{array}$ \\
\hline & 6 & 243 & $1^{\text {er }}$ jan. 1665 & J. Gerbais & $\begin{array}{l}\text { La question de l'auto- } \\
\text { rité du Pape sur le } \\
\text { concile n'appartient } \\
\text { pas à la foi }\end{array}$ \\
\hline & 7 & 256 & $1^{\text {er }}$ mars 1665 & N. Petitpied & $\begin{array}{l}\text { On peut appeler du } \\
\text { Pape au concile }\end{array}$ \\
\hline III & 1 & 262 & $\begin{array}{l}15 \text { mars } \\
1665\end{array}$ & J. Gerbais & $\begin{array}{l}\text { Les papes se } \\
\text { reconnaisssent } \\
\text { faillibles. }\end{array}$ \\
\hline & 2 & 269 & 13 avr. 1665 & M. de Marolles & $\begin{array}{l}\text { L'infaillibilité n'est } \\
\text { pas liée au titre de } \\
\text { « vicaire du Christ » }\end{array}$ \\
\hline & 3 & 281 & 23 mai 1665 & Th. Roulland & $\begin{array}{l}\text { L'Église doit être } \\
\text { gouvernée par les } \\
\text { canons : } 62 \text { témoi- } \\
\text { gnages des papes }\end{array}$ \\
\hline & 4 & 311 & $1^{\text {er }}$ juil. 1665 & J. Maleteste & $\begin{array}{l}\text { Utilité et néces- } \\
\text { sité des conciles } \\
\text { reconnues par } 36 \\
\text { témoignages de } \\
\text { papes }\end{array}$ \\
\hline & 5 & 356 & 5 août 1665 & M. Le Métayer & $\begin{array}{l}\text { Prononcer ex } \\
\text { cathedra }\end{array}$ \\
\hline & 6 & 373 & 13 août 1665 & Ch. Fauveau & $\begin{array}{l}\text { Le Pontife Romain } \\
\text { peut tomber dans } \\
\text { l'erreur }\end{array}$ \\
\hline & 7 & 380 & $1^{\text {er }}$ sept. 1665 & Ch. Fauveau & $\begin{array}{l}\text { Bellarmin ignore } \\
\text { beaucoup de } \\
\text { témoignages contre } \\
\text { l'infaillibilité du Pape }\end{array}$ \\
\hline
\end{tabular}




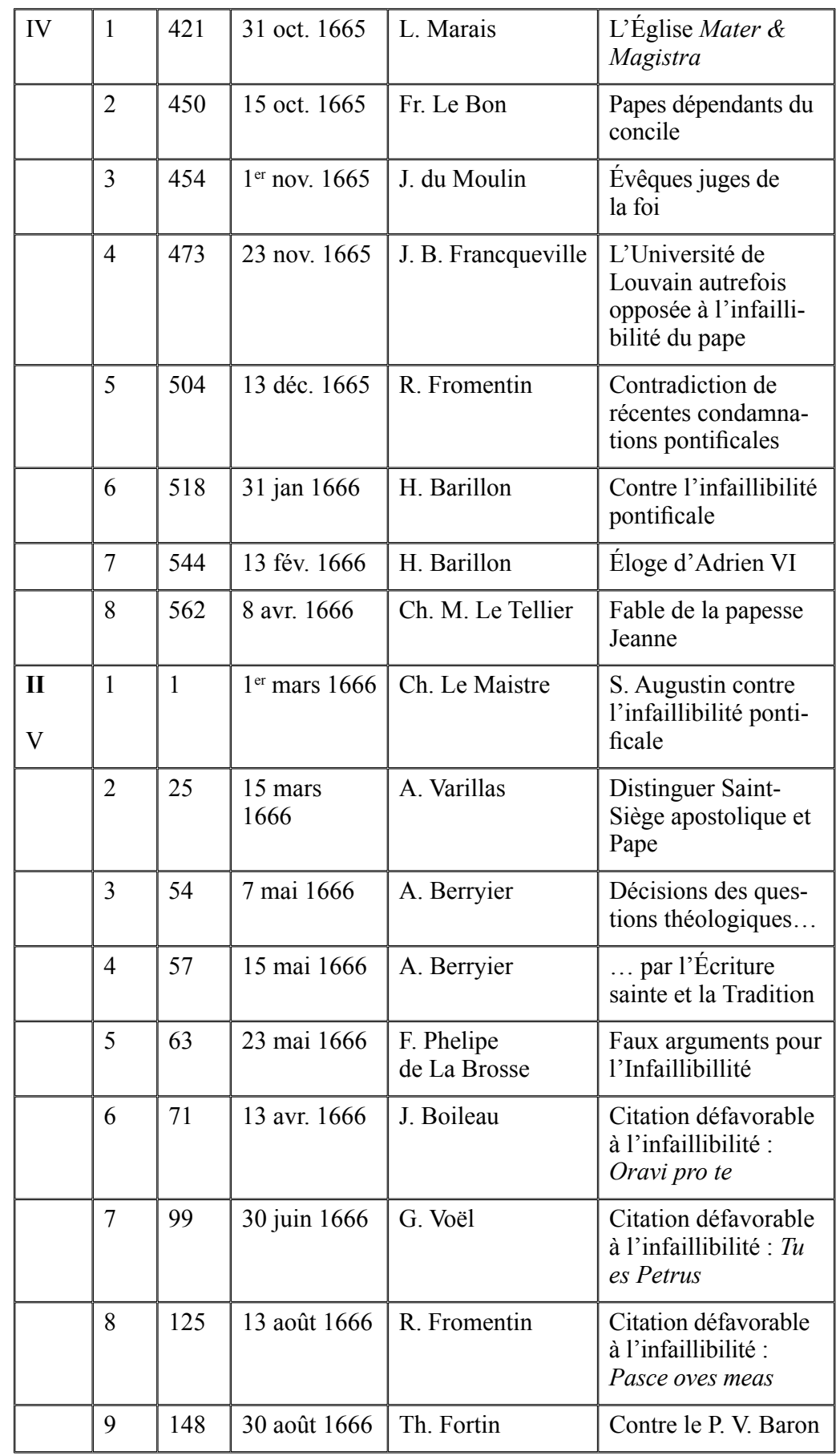




\begin{tabular}{|c|c|c|c|c|c|}
\hline VI & 1 & 208 & 5 déc. 1666 & H. L. Montmort & $\begin{array}{l}\text { Indiction et convo- } \\
\text { cation des conciles : } \\
\text { principes généraux. } \\
\text { Concile de Nicée }\end{array}$ \\
\hline & 2 & 233 & 6 déc. 1666 & H. L. Montmort & $\begin{array}{l}\text { Concile de } \\
\text { Constantinople I }\end{array}$ \\
\hline & 3 & 245 & 23 déc. 1666 & G. Voël & Concile d'Éphèse \\
\hline & 4 & 252 & 13 jan. 1667 & J. Breyer & $\begin{array}{l}\text { Concile de } \\
\text { Calcédoine }\end{array}$ \\
\hline & 5 & 273 & 18 jan. 1667 & M. de Marolles & $\begin{array}{l}\text { Concile de } \\
\text { Constantinople II (V } \\
\text { Concile) }\end{array}$ \\
\hline & 6 & 279 & 21 jan 1667 & J. Maleteste & $\begin{array}{l}\text { Concile de } \\
\text { Constantinople III } \\
\left(\mathrm{VI}^{\mathrm{e}} \text { Concile) }\right.\end{array}$ \\
\hline & 7 & 285 & 19 jan. 1667 & L. Faye d'Espesse & $\begin{array}{l}\text { Concile de Nicée II } \\
\text { (VII }{ }^{\mathrm{e}} \text { Concile) }\end{array}$ \\
\hline & 8 & 292 & 28 jan. 1667 & J. Sainte-Beuve & $\begin{array}{l}\text { Concile de } \\
\text { Constantinople IV } \\
\text { (VIII }{ }^{\mathrm{e}} \text { Concile) }\end{array}$ \\
\hline & 9 & 295 & 27 jan. 1667 & R. Fromentin & Concile de Florence \\
\hline & 10 & 297 & 13 fév. 1667 & Th. Roulland & $\begin{array}{l}\text { Contre Bellarmin : } \\
\text { trois principes }\end{array}$ \\
\hline & 11 & 299 & 25 fév. 1667 & L. Cousin & $\begin{array}{l}\text { Application au } \\
\text { concile de Trente }\end{array}$ \\
\hline & 12 & 302 & 7 mars 1667 & J. Boileau & $\begin{array}{l}\text { Maxime favorable } \\
\text { au pape }\end{array}$ \\
\hline & 13 & 309 & $1^{\text {er }}$ avr. 1667 & A. Faure & $\begin{array}{l}\text { Critique du Dictatus } \\
\text { Papce de Grégoire } \\
\text { VII }\end{array}$ \\
\hline & 14 & 319 & $1^{\text {er }}$ août 1667 & L. Marais & $\begin{array}{l}\text { Réplique en } 21 \\
\text { remarques à la } \\
\text { réponse du P. Baron }\end{array}$ \\
\hline VII & 1 & 412 & 7 oct. 1669 & M. Girard & $\begin{array}{l}\text { Fausseté des privi- } \\
\text { lèges de St-Médard } \\
\text { de Soissons }\end{array}$ \\
\hline & 2 & 430 & 15 oct. 1669 & M. Girard & $\begin{array}{l}\text { Contre la confirma- } \\
\text { tion des synodes dio- } \\
\text { césains par le pape }\end{array}$ \\
\hline & 3 & 440 & 15 mars 1670 & J. Barillon & $\begin{array}{l}\text { Tombeau d'un } \\
\text { chanoine }\end{array}$ \\
\hline
\end{tabular}




\begin{tabular}{|c|c|c|c|c|c|}
\hline & 4 & 441 & 13 avr. 1670 & C. d'Estrées & $\begin{array}{l}\text { Épitaphe d'un } \\
\text { chanoine }\end{array}$ \\
\hline & 5 & & 14 mai 1670 & Ch. Vairon & Son Épitaphe \\
\hline & 6 & 445 & 30 mai 1670 & J. Roland & $\begin{array}{l}\text { Fausseté des privi- } \\
\text { lèges d'Autun }\end{array}$ \\
\hline & 7 & 456 & 13 juin 1670 & J. Roland & $\begin{array}{l}\text { Déposition des rois } \\
\text { par les papes }\end{array}$ \\
\hline & 8 & 475 & $1^{\text {er juil. } 1670}$ & Ch. Presty & $\begin{array}{l}\text { Déposition des rois } \\
\text { hérétiques par les } \\
\text { papes }\end{array}$ \\
\hline & 9 & 477 & 20 juin 1670 & L. Marais & $\begin{array}{l}\text { Déposition des rois } \\
\text { par les papes }\end{array}$ \\
\hline & 10 & 487 & 15 juil. 1670 & Cl. Ameline & $\begin{array}{l}\text { Déposition des rois } \\
\text { par les papes }\end{array}$ \\
\hline & 11 & 494 & 15 juil. 1670 & R. Fromentin & Puissance spirituelle \\
\hline VIII & 1 & 553 & $1^{\text {er }}$ fév. 1673 & R. Fromentin & $\begin{array}{l}\text { Présidence des } 8 \\
\text { premiers conciles } \\
\text { généraux }\end{array}$ \\
\hline & 2 & 572 & 13 fév. 1673 & R. de Bourges & $\begin{array}{l}\text { Présidence des } 8 \\
\text { premiers conciles : } \\
\text { Sardique }\end{array}$ \\
\hline & 3 & 575 & $1^{\mathrm{er}} \operatorname{mars} 1673$ & G. Grouyn & $\begin{array}{l}\text { Présidence des } 8 \\
\text { premiers conciles : } \\
\text { Constantinople I }\end{array}$ \\
\hline & 4 & 581 & 15 mars 1673 & A. Faure & $\begin{array}{l}\text { Présidence des } 8 \\
\text { premiers conciles : } \\
\text { Éphèse }\end{array}$ \\
\hline & 5 & 594 & 13 avr. 1673 & Th. Roulland & $\begin{array}{l}\text { Présidence des } 8 \\
\text { premiers conciles : } \\
\text { Éphèse [II] }\end{array}$ \\
\hline & 6 & 600 & 13 avr. 1673 & L. Cousin & $\begin{array}{l}\text { Présidence des } 8 \\
\text { premiers conciles : } \\
\text { Calcédoine }\end{array}$ \\
\hline & 7 & 607 & 12 mai 1673 & Ch. Presty & $\begin{array}{l}\text { Présidence des } 8 \\
\text { premiers conciles : } \\
\text { Constantinople II }\end{array}$ \\
\hline & 8 & 609 & 13 avr. 1673 & J. Gerbais & $\begin{array}{l}\text { Présidence des } 8 \\
\text { premiers conciles : } \\
\text { Constantinople III }\end{array}$ \\
\hline
\end{tabular}




\begin{tabular}{|c|c|c|c|c|c|}
\hline & 9 & 615 & 30 avr. 1673 & J. Sainte-Beuve & $\begin{array}{l}\text { Présidence des huit } \\
\text { premiers conciles : } \\
\text { Nicée II }\end{array}$ \\
\hline & 10 & 618 & 7 mai 1673 & Fr. Le Bon & $\begin{array}{l}\text { Présidence des huit } \\
\text { premiers conciles : } \\
\text { Constantinople IV }\end{array}$ \\
\hline & 11 & 621 & 15 mai 1673 & Cl. Ameline & $\begin{array}{l}\text { Définition et nombre } \\
\text { des conciles généraux }\end{array}$ \\
\hline & 12 & 632 & $1^{\text {er }}$ juin 1673 & L. Gondrin & $\begin{array}{l}\text { Dignité et droits des } \\
\text { métropolitains }\end{array}$ \\
\hline & 13 & 665 & 22 juin 1673 & N. Gatineau & $\begin{array}{l}\text { Définition de } \\
\text { l’Église }\end{array}$ \\
\hline & 14 & 696 & $1^{\text {er }}$ août 1673 & L. Marais & $\begin{array}{l}\text { Comment régler les } \\
\text { disputes théolo- } \\
\text { giques }\end{array}$ \\
\hline & 15 & 735 & $1^{\text {er }}$ sept. 1673 & J. Boileau & $\begin{array}{l}\text { Défense de S. } \\
\text { Cyprien sur la ques- } \\
\text { tion du baptême }\end{array}$ \\
\hline & 16 & 772 & 27 oct. 1655 & J. A. Portnoir & $\begin{array}{l}\text { Sur la mort de P. } \\
\text { Gassendi }\end{array}$ \\
\hline Sup. & 1 & 777 & 28 mars 1629 & Un ami & $\begin{array}{l}\text { Utilité du concile de } \\
\text { Trente }\end{array}$ \\
\hline & 2 & 783 & s. d. & Un ami & 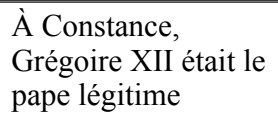 \\
\hline & 3 & 789 & s. d. & Un ami & $\begin{array}{l}\text { La Faculté de Paris } \\
\text { sur la contrition } \\
\text { [Affaire Seguenot] }\end{array}$ \\
\hline & 4 & 806 & 15 mai 1661 & L. Bail & $\begin{array}{l}\text { Traductions de } \\
\text { l'Écriture permises } \\
\text { aux laïcs }\end{array}$ \\
\hline & 5 & 813 & $1^{\text {er }}$ mai 1677 & N. Le Noir & $\begin{array}{l}\text { Empêchements } \\
\text { dirimants }\end{array}$ \\
\hline & 6 & 820 & 12 mai 1677 & L. Cousin & $\begin{array}{l}\text { Mariage entre } \\
\text { cousins }\end{array}$ \\
\hline & 7 & 827 & 16 mai 1677 & $\mathrm{~N}$. & $\begin{array}{l}\text { Dispenses matrimo- } \\
\text { niales de Grégoire I }\end{array}$ \\
\hline & 8 & 830 & 30 mai 1677 & Fr. Le Bon & $\begin{array}{l}\text { Mariage comme } \\
\text { contrat }\end{array}$ \\
\hline & 9 & 833 & 5 juin 1677 & J. Sainte-Beuve & $\begin{array}{l}\text { Degrés de consan- } \\
\text { guinité }\end{array}$ \\
\hline
\end{tabular}




\section{Ses correspondants}

Pour les gradués de la Faculté de théologie de Paris, le $\mathrm{n}^{\circ}$ entre crochets donne l'année et le rang de la licence, il correspond à un registre à paraître.

Claude Ameline (1633-1708), chantre de Notre-Dame, curé de SaintPierre-aux-bœufs : vii-10, viii-11.

Louis Bail (†1671), Chol. [1628-12], curé de Montmartre : Sup.-4.

Henri de Barrillon (1639-1699), [1668-81], évêque de Luçon : iv-6, iv-7. Jean-Jacques Barrillon (†1683), prieur de Gizy : vii-3.

André Berryier : v-3, v-4.

Jacques Boece, Vict. : ii-3

Jacques Boileau (1635-1716), Sorb. [1662-1], doyen de Sens : ii-4, v-6, vi-12.

René de Bourges [1668-45] : viii-2.

Jean Breyer (†1690), [1658-35], théologal de Dax : vi-4.

Louis Cousin (1627-1707), bachelier en théologie, président à la Cour des Monnaies : i-8, vi-11, viii-6, Sup.-6.

Louis [Henri] Faye Despesses [1646-51], abbé de Saint-Pierre de Vienne : vi-7.

César d'Estrées (1628-1714), évêque de Laon (1653-1681), cardinal (1672) : vii-4.

Jean du Moulin [1664- 26], primicier de Metz : iv-3,

Antoine Faure (†1689), [1658-23], principal du collège Saint-Michel : i-1, i-2, vi-13, vii-4.

Christophe Fauveau, Nav. [1632-11], official de Poitiers : i-10, iii-6, iii-7. Thomas Fortin (1620-1680), [1646-12], principal du collège d'Harcourt : v-9.

Jean-Baptiste de Francqueville $(\dagger 1715)$, grand chantre de Cambrai : iv-4. Raymond Fromentin (†1703), Sorb. [1660-9], chanoine d'Orléans : i-5, ii-1, v-8, vi-9, vii-11, viii-1.

Nicolas Gatineau (1620-1696) : viii-13.

Jean Gerbais (1629-1699), Sorb. [1660-23], principal du collège de Reims : ii-6, iii-1, viii-8.

Michel Girard (1600-1674), abbé de Verteuil : vii-1, vii-2.

Louis Henri de Pardailhan de Gondrin (1620-1674), archevêque de Sens : viii-12.

Germain Grouyn [1666-62], chanoine d'Orléans : viii-3.

Félix Phelippes de La Brosse (†1698), [1658-14] : i-6, ii-2, v-5.

François Le Bon, archidiacre de Soissons, cum Launoio conjunctissime vixit [V-28] : 1-4, iv-2, viii-10, Sup.-8.

Charles Le Maistre (†1688), Nav. [1652-11] : v-1. 
Martin Le Métayer (1625-1704), bachelier exclu de la Licence (1656), curé de Saint-Thomas, Évreux : iii-5.

Nicolas Le Noir (†1695), Sorb. [1672-25], curé de Saint-Aspais, Melun : Sup.-5.

Charles Maurice Le Tellier (1642-1710), [1666-1], archevêque de Reims : iv-8.

Adrien Le Vaillant, Nav. [1634-5], chanoine de Reims : ii-5.

Jacques Maleteste [1660-11], chanoine de la Chapelle royale de Dijon : iii-4, vi-6.

Louis Marais (†1687) [1660-26], curé de Saint-Jean-le-rond : i-11, iv-1, vi-14, vii-9, viii-14.

Michel de Marolles (1600-1681), abbé de Villeloin : vi-2, vi-5.

Henri Louis Habert de Montmort $(† 1679)$, maître des requêtes, « mécène des docteurs $\gg$ : vi-1, vi-2.

Nicolas Petitpied (1630-1703), Sorb. [1658-15], curé de Saint-Martial.

Jean Albert Portnoir [?], conseiller de Ratisbonne : viii-16.

Charles Presty (†1680), [1668-21], curé de Liancourt; vii-8, viii-7.

Paul Ratouyn (†1693), [1660-15] : i-3.

Jean Roland [1668-72], chanoine de Reims : vi-6, vi-7.

Thomas Roulland (†1704), [1664-7], grand vicaire de Reims : iii-3, vi-10, viii-5.

Jérôme de Sainte-Beuve (1626-1717), prieur de Montauriol : vi-2, viii-9, Sup.-9.

Claude Santeuil (1628-1686), demeurait à St-Magloire : i-7.

Charles Vairon, chanoine de Laon : [Son épitaphe] vii-5.

Antoine Varillas (1624-1696), historien : v-2.

Guillaume Voël, canoniste parisien : v-7, vi-3. 